\title{
Importance of apoptosis in the histopathology of drug related lesions in the large intestine
}

\author{
F D Lee
}

\begin{abstract}
Aim: To investigate the possibility that the incidence of apoptotic bodies in the cryptal epithelium might help to identify colonic lesions due to drugs, especially non-steroidal anti-inflammatory drugs (NSAIDs).

Methods: The apoptotic count (AC) the number of apoptotic bodies per 100 crypts was calculated in a series of colorectal biopsy specimens, stained with haematoxylin and eosin from patients with (a) known or suspected drug induced colitis and (b) inflammatory bowel disease before or after treatment with salazopyrine or corticosteroids. These specimens were compared with normal biopsy specimens from a control group of comparable age and sex distribution.

Results: Under normal conditions apoptotic bodies were seldom seen at all and the mean apoptotic count was less than $1 \cdot 0$. In untreated inflammatory bowel disease the mean apoptotic count was marginally increased $(2 \cdot 4)$, but when there was a partial response to drug treatment the apoptotic count rose to 13.1 (p 0.003). In colonic lesions directly attributable to drugs the apoptotic count was always increased, reaching its highest level (106) with 5-fluorouracil. In colitis related to NSAIDs apoptoses were associated with inflammation, most notably an increase in lymphocytes in both lamina propria and epithelium.

Conclusion: The presence of crypt apoptoses in substantial numbers (with an apoptotic count in excess of 5) should always raise the possibility of drug effect. The mechanisms involved are not clear but with NSAIDs the changes might well be immunologically mediated.
\end{abstract}

(F Clin Pathol 1993;46:118-122)

The aetiological importance of therapeutic agents in intestinal disease distal to the duodenum is becoming increasingly apparent. With certain drugs, most notably the cytotoxic agents, intestinal disturbance is an accepted hazard and the pathological changes have been reasonably well documented. ${ }^{1}$ In other contexts, however, it is often difficult to establish beyond reasonable doubt that intestinal lesions are caused by drugs. This is especially true of non-steroidal anti-inflammatory drugs (NSAIDs) which have been incriminated in such diverse conditions as ileal ulceration, ${ }^{2}$ diaphragm disease of the small bowel, ${ }^{3}$ non-specific colitis, ${ }^{4}$ colonic perforation $^{5}$ and jejunal villous atrophy with malabsorption. ${ }^{6}$ This list would no doubt be expanded if some kind of objective histological marker for drug effects could be identified, particularly with regard to colorectal biopsy specimens.

The peculiar form of cell dissolution sometimes referred to especially in its physiological context as apoptosis ${ }^{7}$ is well recognised to take place in the epithelium of the intestinal crypts and gastric pits during the graft versus host reaction which may complicate bone marrow transplantation. ${ }^{89}$ Similar changes have also been seen in the colonic lesions in association with AIDS ${ }^{1011}$ and in inflammatory bowel disease. ${ }^{10}$ It has long been known, however, that apoptosis of the colonic epithelium may follow the administration of certain cytotoxic agents, most notably 5-fluorouracil. ${ }^{12}$ There is also experimental evidence that melanosis coli may be related to anthroquinone induced apoptosis of colonic epithelial cells. ${ }^{13}$

The possibility that the presence of apoptosis especially in the colonic crypts might be indicative of exposure to other drugs, and in particular to NSAIDs, was raised by two groups of personal observations. First, apoptosis was found to be a conspicuous feature in cases of colitis related beyond reasonable doubt to the administration of mefenamic acid and diclofenac (voltarol). Secondly during a review of biopsy specimens from patients with putative inflammatory bowel disease (IBD) the impression was gained that apoptosis was more often seen in treated than untreated cases. It was thus considered appropriate to amplify these observations to assess the possible value of apoptosis in the identification of drug induced intestinal disease.

\section{Methods}

All the colorectal biopsy specimens from cases of colitis considered on clinical grounds to be predominantly or exclusively drug induced were retrieved from files of the Pathology Department, Glasgow Royal Infirmary, covering the years 1981 to 1988 . Clinical suspicion was based on either a clear association between drug administration and the onset of colonic symptoms or clinical and pathological evidence that the lesions remitted following withdrawal of the drug. There were numerous
Correspondence to: F D Lee

Accepted for publication 12 August 1992 
Table 1 Clinical and pathological features observed in five cases of drug related colonic disease

\begin{tabular}{|c|c|c|c|c|c|c|}
\hline \multirow{2}{*}{$\begin{array}{l}\text { Case } \\
\text { No }\end{array}$} & \multirow[b]{2}{*}{ Age/sex } & \multirow[b]{2}{*}{ Clinical features } & \multirow{2}{*}{ Drug implicated } & \multicolumn{3}{|c|}{ Histological features } \\
\hline & & & & $A C$ & Inflammation & Other features \\
\hline 1 & $71 \mathrm{M}$ & $\begin{array}{l}\text { Rectal carcinoma Diarrhoea } \\
\text { clearly related to chemotherapy }\end{array}$ & 5-fluorouracil & 106 & & \\
\hline 2 & $51 \mathrm{M}$ & $\begin{array}{l}\text { Gastric carcinoma Diarrhoea and } \\
\text { rectal bleeding clearly related to } \\
\text { chemotherapy }\end{array}$ & $\begin{array}{l}\text { 5-fluorouracil } \\
\text { Adriamycin } \\
\text { Mitomycin }\end{array}$ & $8 \cdot 7$ & $\begin{array}{l}\text { Plasmacytosis in } \\
\text { lamina propria } \\
\text { Margination of } \\
\text { neutrophils }\end{array}$ & $\begin{array}{l}\text { Nuclear atypia } \\
\text { in epithelium } \\
\text { Crypt thinning }\end{array}$ \\
\hline 3 & $40 \mathrm{~F}$ & $\begin{array}{l}\text { Migraine Diarrhoea, abdominal pain } \\
\text { anorexia, weight loss for } 6 \text { months } \\
\text { Symptoms improved and biopsy specimen } \\
\text { returned to normal on drug withdrawal } \\
\text { No pathogens isolated }\end{array}$ & $\begin{array}{l}\text { Mefenamic } \\
\text { acid }\end{array}$ & $7 \cdot 8$ & $\begin{array}{l}\text { Lymphocytosis in } \\
\text { lamina propria: } \\
\text { also neutrophils }\end{array}$ & $\begin{array}{l}\text { IEL focally } \\
\text { increased in } \\
\text { crypts }\end{array}$ \\
\hline 4 & $64 \mathrm{~F}$ & $\begin{array}{l}\text { Diverticular disease: rectal bleeding } \\
\text { No pathogens isolated Symptoms } \\
\text { improved and biopsy specimen returned } \\
\text { to normal on withdrawal of drug }\end{array}$ & $\begin{array}{l}\text { Diclofenac } \\
\text { sodium } \\
\text { (voltarol }\end{array}$ & 23.9 & $\begin{array}{l}\text { Plasma cells, lymphocytes } \\
\text { increased in } \\
\text { lamina propria, } \\
\text { occasional neutrophils }\end{array}$ & $\begin{array}{l}\text { IEL focally } \\
\text { increased in } \\
\text { crypts also } \\
\text { intraepithelial } \\
\text { eosinophils } \\
\text { Crypt abscess } \\
\text { formation }\end{array}$ \\
\hline 5 & $70 \mathrm{~F}$ & $\begin{array}{l}\text { Chronic osteoarthritis Diarrhoea, } \\
\text { which improved on withdrawal of drug } \\
\text { No pathogens isolated }\end{array}$ & $\begin{array}{l}\text { Mefenamic } \\
\text { acid }\end{array}$ & $5 \cdot 7$ & $\begin{array}{l}\text { Plasma cells, lymphocytes, } \\
\text { eosinophils increased } \\
\text { in lamina propria }\end{array}$ & $\begin{array}{l}\text { IEL focally } \\
\text { increased in } \\
\text { crypts: also } \\
\text { intraepithelial } \\
\text { eosinophils }\end{array}$ \\
\hline
\end{tabular}

$\mathrm{AC}=$ apoptosis count

IEL $=$ intra-epithelial lymphocytes

cases of colitis in which drug effects were suspected, but only five cases fulfilled these strict criteria (table 1).

All the colorectal biopsy reports from cases of non-specific inflammatory bowel disease for the years 1986 to 1987 were also reviewed. These cases were divided into two main groups. The first consisted of patients undergoing initial investigation for colonic symptoms and whose biopsy specimens were consistent with those of IBD in an active phase, as revealed by the presence of cryptitis - that is, neutrophil infiltration of the crypt epithelium-in addition to plasmacytic infiltration in the lamina propria. This was designated the presumptive untreated group and comprised 32 cases (male female ratio 13:19, mean age 47 years, range $21-78$ years). The second consisted of patients with IBD who were being treated with either salazopyrine ( 5 cases), or steroids ( 9 cases), or both (6 cases). In all of these cases the diagnosis had been reasonably well established from previous biopsy analysis and clinical investigation. The duration of the disease varied from a few

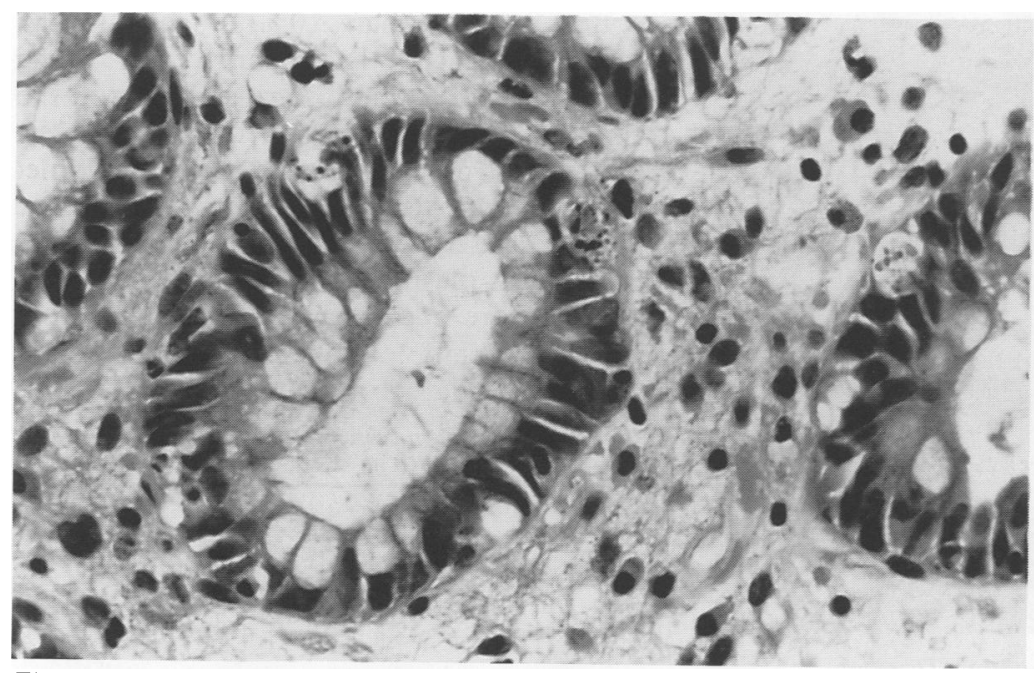

Figure 1 Rectal mucosa during treatment with 5-fluoroouracil. Apoptosis bodies are clearly seen (haematoxylin and eosin). weeks to 16 years and several patients had experienced multiple relapses. This treated group (20 cases in all; male female ratio 3:13, mean age 39 years, range 11 to 59 years) was further subdivided into those cases in which the disease was deemed, on histological grounds, to be in remission by virtue of an absence of leucocytic infiltration beyond that observed normally (9 cases) and those cases showing persistent active or chronic inflammatory reaction (11 cases). The latter were regarded as being in a "partial response". There was no significant difference in the mean duration of treatment between those cases in remission (15.6 months) and those showing a partial response $(12 \cdot 1$ months).

For control purposes a random series of 20 histologically normal rectal biopsy specimens from patients with non-specific colonic symptoms, such as unexplained diarrhoea or constipation, rectal bleeding, abdominal pain, was extracted from the 1986 files. This normal group included seven males and 13 females, the mean age being 44 years (range 13 to 74 years). A group of biopsy specimens from other colonic diseases were also assessed; these included melanosis coli (5 cases) infective colitis ( 4 cases), and radiation colitis ( 6 cases). The last condition was divided into a chronic type-presenting 18 months or more following irradiation (4 cases)-and an acute type-observed 10-14 days following irradiation in preparation for surgical treatment for rectal carcinoma ( 2 cases).

All the specimens had been fixed in neutral buffered formalin and processed by standard methods. In each case three or more $5 \mu \mathrm{m}$ sections stained with haematoxylin and eosin were available, the best orientated being selected for calculation of the apoptosis count. The procedure for this is simple but relies on positive identification of the structure known as an apoptotic body within the epithelium lining the lower half of the crypts of Lieberkühn. Apoptotic bodies vary in appearance, but for the purposes of this study were defined as round or ovoid structures 


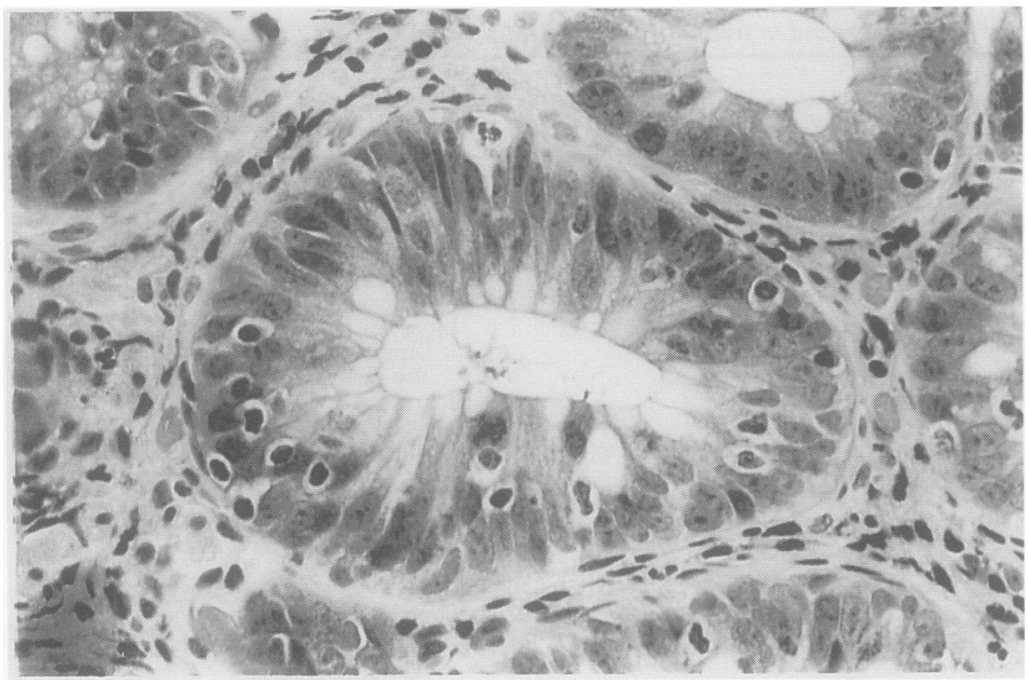

Figure 2 Rectal mucosa following exposure to mefenamic acid. Note the increase in intraepithelial lymphocytes and the goblet cell depletion, albeit of minor degree. An apoptotic body can also be seen (haematoxylin and eosin).

apparently bounded by a discrete membrane and enclosing aggregates of pyknotic intensely basophilic fragments of nuclear chromatin often surrounded by a thin mantle of cytoplasm (fig 1). Isolated fragments of pyknotic basophilic material are quite often seen in biopsy specimens but are not included in the counts: they often indicated, however, that apoptotic bodies might be present in the vicinity. Almost all biopsy specimens had evidence of nuclear fragments (usually within histocytes) beneath the surface epithelium. These are particularly prominent in colonoscopic biopsy specimens and are not included in the study. Another problem encountered was the distinction between apoptotic bodies and intraepithelial neutrophils; this did not usually cause great difficulty but in cases of doubt the lesion in question was omitted from the count. All the apoptotic bodies found within the location designated above were counted in each biopsy specimen. The total numbers of crypts were also counted and the number of apoptotic bodies per 100

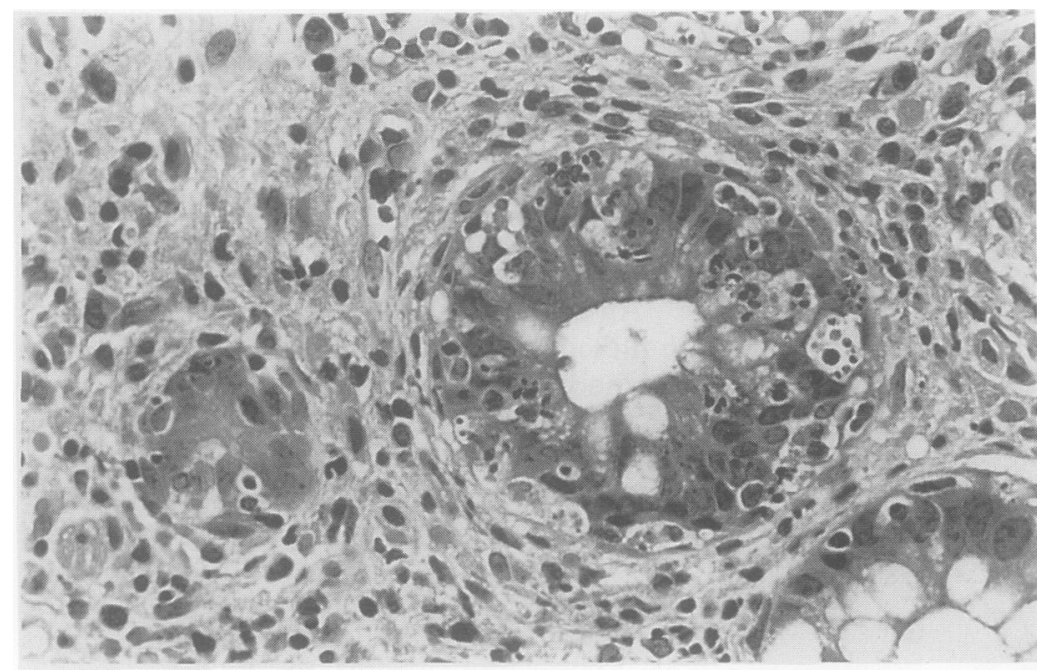

Figure 3 Rectal mucosa in colitis associated with diclofenac treatment. There are numerous apoptotic bodies. Intra-epithelial lymphocytes are also easily found and account for $10 \%$ of the cells in the epithelial surface (haematoxylin and eosin). crypts was calculated. This was referred to as the apoptotic count. The number of crypts counted varied between 17 and 325. Most of the low counts were found in cases of untreated IBD in which there was extensive crypt damage or dissolution. It is possible that this may have biased the results, but in untreated IBD the mean apoptosis count per case was almost identical with that obtained by aggregating the measurements made in all cases.

The results were analysed using the MannWhitney Wilcoxon two sample rank test.

\section{Results}

These are summarised in tables 1 and 2 . In the normal group (table 2) the mean apoptosis count was 0.94 (mean SE 0.7 ); in only four of the $20(25 \%)$ cases were apoptotic bodies found at all, the highest count recorded being $7 \cdot 8$.

In the cases of drug induced colitis (table 1) the apoptosis count was equal to or above the normal range with the exception of one case of mefenamic acid induced colitis in which the apoptosis count was $5 \cdot 7$. The histological features of the rectal mucosa in these cases were variable. As far as cytotoxic agents are concerned the biopsy specimen exposed to 5-fluoro-uracil alone (case 1) showed little deviation from normal despite the high apoptosis count (106; fig 1). With the combination of 5-FU with other agents (case 2) there is plain evidence of epithelial damage as revealed by etiolation of the crypts, and flattening of the surface epithelium and nuclear atypia. There is also a mild plasmacytosis of the lamina propria with pronounced margination of neutrophils accompanied by oedema and vascular congestion. With the other drugs implicated, all NSAIDs, the inflammatory changes are more pronounced. Mefenamic acid (cases 3 and 5) produces a sharp increase in lymphocytes in the lamina propria and there is also a distinct increase in intraepithelial lymphocytes (accounting for, respectively, 18\% and 10\% of the total number of cells in the epithelial layer). Normally, intraepithelial lymphocytes account for less than $10 \%$ of cells in the epithelial surface, the mean count being $4 \cdot 7 \% .{ }^{16}$ Some neutrophils are also seen in the epithelium but there are no crypt abscesses. Even so the crypts show substantial goblet cell depletion (fig 2). With diclofenac (voltarol; case 5) the inflammatory changes in which both plasma cells and lymphocytes participate are accompanied by more severe

Table 2 Incidence of crypt apoptoses in normal rectal biopsy specimens and in those from untreated and treated IBD

\begin{tabular}{|c|c|c|c|c|}
\hline & \multirow[t]{2}{*}{$N$} & \multicolumn{2}{|l|}{ Apoptosis count } & \multirow{2}{*}{$\begin{array}{l}\text { Percentage of } \\
\text { cases with } \\
\text { apoptosis }\end{array}$} \\
\hline & & Mean & Range & \\
\hline $\begin{array}{l}\text { Normal } \\
\text { IBD, untreated } \\
\text { IBD, partial }\end{array}$ & $\begin{array}{l}20 \\
32\end{array}$ & $\begin{array}{r}0.94(\text { SE } 0.5) \\
2.4(\text { SE } 0.7)\end{array}$ & $\begin{array}{l}0-7 \cdot 8 \\
0-14 \cdot 3\end{array}$ & $\begin{array}{l}20 \\
56\end{array}$ \\
\hline $\begin{array}{l}\text { response phase } \\
\text { IBD, remission }\end{array}$ & $\begin{array}{r}11 \\
9\end{array}$ & $\begin{array}{r}13.1(\text { SE } 3.3) \\
1.4(\text { SE } 1.1)\end{array}$ & $\begin{array}{l}0-34 \cdot 3 \\
0-9 \cdot 7\end{array}$ & $\begin{array}{l}91 \\
44\end{array}$ \\
\hline
\end{tabular}


tion and even crypt dissolution. Again an increase in intra-epithelial lymphocytes occurred (fig 3). In cases 4 and 5 eosinophils were quite prominent and were also found within the crypt epithelium. In none of the cases, however, was there the kind of crypt irregularity seen in IBD.

In untreated IBD (table 2) the mean apoptosis count was 2.4 (SE 0.658 ) which was only just significantly greater than that in the normal group $(p=0.085)$. Apoptosis was observed in $56 \%$ of the cases. There was no significant difference between ulcerative colitis and Crohn's disease in this regard, the mean apoptosis count counts being 2.6 and $2 \cdot 2$, respectively. In the "partial response" phase of IBD the mean apoptosis count rises to $13 \cdot 1$ (SE 3.34) which was significantly greater than that found in untreated cases $(p$ $=0.011$ ). The small numbers available made it impossible to measure exactly the influence of specific forms of treatment: in general terms, however, treatment schedules including salazopyrine gave the highest counts (mean apoptosis count $18 \cdot 8$ ). With steroids alone the apoptosis count was $6 \cdot 2$, and in the sole case in which only salazopyrine was given the apoptosis count was $29 \cdot 6$. When the tissue enters remission, however, the apoptosis count falls to almost normal levels (1.4; SE1.5) and in over $50 \%$ of cases apoptotic bodies could not be found at all. The number of cases in each of the miscellaneous groups was too small to produce significant results but apart from acute radiation colitis these were not dramatic.

In melanosis coli the apoptosis count in the five cases examined varies considerably $(6 \cdot 2$, $2 \cdot 3,0,0,3 \cdot 0$ ). This was also the case with infective colitis; the apoptosis count was zero in two cases of amoebic colitis and in the solitary case of bacillary dysentery. In one case of campylobacter colitis, however, an apoptosis count of 9.5 was recorded. The biopsy specimens in the four cases of chronic radiation colitis were too small to measure with any conviction: two gave zero counts but the apoptosis count was 5 in each of the two other cases. In contrast, the apoptosis count in the two cases of acute radiation colitis was 20.5 and 14.0 , respectively. In both instances there was extensive crypt damage associated with pronounced nuclear atypia, cytomegaly, and abnormal mitotic activity in the epithelial cells. Eosinophilic infiltration into the crypt epithelium and lamina propria (and sometimes deeper) was another notable feature.

\section{Discussion}

In circumstances which might be regarded as physiological the phenomenon of apoptosis is sometimes referred to as programmed cell death. ${ }^{14}$ In the colonic mucosa it might be anticipated that under normal conditions apoptotic bodies would be restricted to the surface epithelium as epithelial cells reach the end of their natural lifespan; and this indeed was usually the case. It should also be added, however, that in almost any colorectal biopsy specimen (especially when taken during colonoscopy) nuclear fragments can be found beneath the surface epithelium usually within histiocytes which may be abundant in this location. This phenomenon can be so striking as to resemble granuloma formation for which it must not be mistaken. The presence of apoptosis in the crypts, however, cannot be regarded as truly physiological and should persuade the observer to seek a cause even if the biopsy specimen otherwise appears normal.

The main purpose of this study was to explore the possibility that the detection of apoptotic bodies in the colorectal crypts might be of diagnostic relevance particularly with regard to drug induced colonic disturbance. It was appreciated from the outset of course that the presence of apoptotic bodies has been reported in disease states in the apparent absence of drug treatment, AIDS perhaps being the most notable example. ${ }^{1011}$ In the present study it has not only been confirmed that apoptotic bodies may also be found in untreated IBD ${ }^{11}$ but that they may be seen sporadically in infective colitis and even in $20 \%$ of apparently normal biopsy specimens. With some notable exceptions, however, only small numbers of apoptotic bodies can be detected in untreated colorectal disease and do not seem to appear under normal conditions.

It is against this background that the effects of drug treatment on the colonic mucosa have to be assessed. Apoptotic bodies have readily been found in all the reasonably well established cases of drug induced colonic disturbance described in the study. Only in acute radiation colitis does the apoptosis count approach that seen in association with drug treatment. As expected the highest apoptosis count was recorded after treatment with 5fluoro-uracil, ${ }^{12}$ but apoptotic bodies were present in substantial numbers in colitis associated with diclofenac (voltarol) and to a lesser extent in association with lesions induced by mefenamic acid. Moreover in cases of IBD showing only a partial response to treatment the apoptotic count in the colonic mucosa becomes significantly increased over baseline levels, this being especially noticeable with drug regimens which include salazopyrine. It can therefore be asserted that even if the finding of apoptotic bodies in the colorectal mucosal crypt does not have any specific diagnostic meaning, the presence of apoptotic bodies in substantial numbers-in more than five out of 100 crypts - should always raise the possibility of drug effects. This observation may be of value not only in the primary investigation of unexplained colonic inflammation but also in the assessment of biopsy specimens in cases of putative IBD in which there is a possibility that the histological appearance may have been modified by drug treatment.

The mechanisms by which drugs bring about apoptotic change are far from clear. In the cases of colitis associated with NSAIDs and reported in this study cryptal apoptoses 
were frequently accompanied by other histological abnormalities, most notably an increase in lymphocytes in the lamina propria as well as an increase in intraepithelial lymphocytes mainly in the crypts themselves. In some instances there was evidence of more acute crypt damage with incipient or even frank crypt abscess formation. This combination of changes is a little unusual in colorectal biopsy specimens. An increase in intraepithelial lymphocytes has only been recorded in a few conditions such as the lymphocytic variant of microscopic colitis, ${ }^{15-17}$ collagenous colitis, ${ }^{16}$ and coeliac disease following rectal gluten challenge. ${ }^{18}$ An increase in intraepithelial lymphocytes and has also been observed in some cases of inflammatory bowel disease. ${ }^{16}$ The presence of eosinophils as well as lymphocytes in the crypts in some cases of NSAID related colitis is of interest because it raises the possibility that in these instances the drug induced cell damage may well be immunologically mediated and thus represents a hypersensitivity reaction. Indeed, the changes were analogous to those observed in lichenoid drug eruptions in the skin. Whether a similar mechanism is operating in acute radiation colitis, in which eosinophilic infiltration of the crypt epithelium may also be conspicuous, is more doubtful. With cytotoxic agents such as 5-fluoro-uracil apoptosis is more likely to be the result of a direct toxic effect. The appearance of apoptosis during the treatment of IBD is not easy to explain by either of these mechanisms. It may, however, be a "post-hyperplastic" effect ${ }^{19}$ related to temporary overproduction of epithelial cells in the crypts at a time when cell damage is being brought under control by drug treatment. This would explain the fall in the number of apoptoses which takes place when the disease goes into remission even though drug treatment continues.

In summary, it has been shown in the study that although the detection of the occasional apoptotic body in a colorectal crypt may not have any specific diagnostic connotation, the presence of apoptotic bodies in substantial numbers (in more than five of 100 crypts) should always raise the possibility of a drug effect. The mechanisms whereby drugs produce these effects are poorly understood.
In the case of NSAID associated lesions, however, apoptosis is accompanied by inflammatory changes and in particular by a focal increase in intraepithelial lymphocytes in the crypts and may well be immunologically mediated.

I am most grateful to Dr Alfred Pauson for his help in the statistical analysis and to Dr AG Howatson for his advice in the preparation of this paper.

1 Cunningham D, Morgan RJ, Mills PR, et al. Functional and structural changes of the human proximal small intestine after cytotoxic therapy. $\mathcal{f}$ Clin Pathol 1985: 38: intestine

2 Madhok R, McKenzie JF, Lee FD, Bruckner FE, Terry TR, Sturrock RD. Small bowel ulceration in patients receiving non-steroidal anti-inflammatory drugs for rheumatoid arthritis. $Q \mathcal{F}$ Med 1986; 58: 53-8.

3 Lang J, Price AB, Levi AJ, et al. Diaphragm disease: pathology of disease of the small intestine induced by NSAIDS. $f$ Clin Pathol 1988: 41: 516-26.

4 Hall RI, Petty AH, Cobden I, Lendowin R. Enteritis and colitis associated with mefenamic acid. $\mathrm{Br}$ Med $\mathcal{F} 1983$; 287: 1182.

5 Day TK. Intestinal performation association with osmotic slow release indomethacin capsules. $\mathrm{Br}$ Med $f$ 1983; 287: 1671-2.

6 Isaacs PET, Sladen GE, Filipe I. Mefenamic acid enteropathy. F Clin Pathol 1987: 40: 1221-7.

7 Kerr JFR, Bishop CJ, Searle J. Apoptosis. In: Anthony PP, MacSween RNM, EDs. Recent advances in pathology. No 12. London: Churchill Livingstone, 1984: L. 1-16.

8 Epstein RJ, McDonald GB, Sale GE, Shulman HM, Thomas ED. The diagnostic accuracy of the rectal biopsy in acute graft-versus-host disease. A prospective study of thirteen patients. Gastroenterology 1980; 78: 764-71.

9 Gallucci BB, Epstein R, Sale GE, Shulman HM, McDonald GB, Thomas ED. The fine structure of human rectal epithelium in acute graft-versus-host dishuman rectal epithelium in acute graft-vers

10 Kotler DP, Gaetz HP, Lange M, Klein EB, Holt PR. Enteropathy associated with the acquired immunodeficiency syndrome. Ann Intern Med 1984; 101: 421-8.

11 Kotler DP, Weaver SC, Terzakis JA. Ultrastructural features of epithelial cell degeneration in rectal crypts of patients with AIDS. Am $\mathcal{F}$ Surg Pathol 1986: 10: 531-8.

12 Floch MH, Hellman L. The effect of 5-fluorouracil on rectal mucosa. Gastroenterology 1965; 48: 430-7.

13 Walker NI, Bennett RE, Axelsen RA. Melanosis coli. A consequence of anthroquinone induced apoptosis of

14 Wyllie AH. Commentary: What is apoptosis? Histopathology 1986, 10: 995-8.

15 Ong G, Price AB. Microscopic (lymphocytic) colitis: characteristic rectal biopsy features. $\mathcal{F}$ Pathol 1990; 160 $170 \mathrm{~A}$

16 Lazenby AJ, Yardley JH, Giardiello FM, Jessurun J, Bayless TM. Lymphocytic (microscopic) colitis. Hum Pathol 1989; 20: 18-28.

17 Giardiello FM, Lazenby AJ, Bayless TM, et al. Lymphocytic (microscopic) colitis. Dig Dis Sci 1989; 34: 1730-8.

18 Austin LL, Dobbins WO. Studies of the rectal mucosa in coeliac sprue: the intraepithelial lymphocyte. Gut 1988; 29: 200-5.

19 Ledda-Columbano GM, Columbano A, Coni P, Faa G, Pani $P$. Cell deletion by apoptosis during regression of renal hyperplasia. Am $\mathcal{F}$ Pathol 1989; 135: 657-62. 